
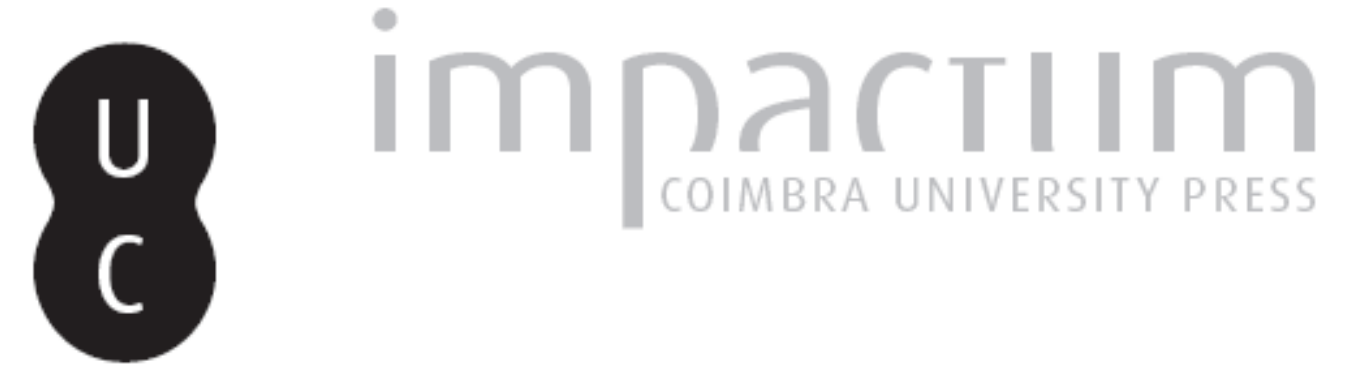

[Recensão a] Francisco Régis Lopes Ramos, A poeira do passado. Tempo, saudade e cultura material
Autor(es):
Torgal, Luís Reis

Publicado por: Imprensa da Universidade de Coimbra

URL persistente:

URl:http://hdl.handle.net/10316.2/40222

DOI:

DOI:https://doi.org/10.14195/2183-8925_34_13

Accessed : $\quad$ 26-Apr-2023 09:14:28

A navegação consulta e descarregamento dos títulos inseridos nas Bibliotecas Digitais UC Digitalis, UC Pombalina e UC Impactum, pressupõem a aceitação plena e sem reservas dos Termos e Condições de Uso destas Bibliotecas Digitais, disponíveis em https://digitalis.uc.pt/pt-pt/termos.

Conforme exposto nos referidos Termos e Condições de Uso, o descarregamento de títulos de acesso restrito requer uma licença válida de autorização devendo o utilizador aceder ao(s) documento(s) a partir de um endereço de IP da instituição detentora da supramencionada licença.

Ao utilizador é apenas permitido o descarregamento para uso pessoal, pelo que o emprego do(s) título(s) descarregado(s) para outro fim, designadamente comercial, carece de autorização do respetivo autor ou editor da obra.

Na medida em que todas as obras da UC Digitalis se encontram protegidas pelo Código do Direito de Autor e Direitos Conexos e demais legislação aplicável, toda a cópia, parcial ou total, deste documento, nos casos em que é legalmente admitida, deverá conter ou fazer-se acompanhar por este aviso.

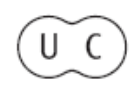



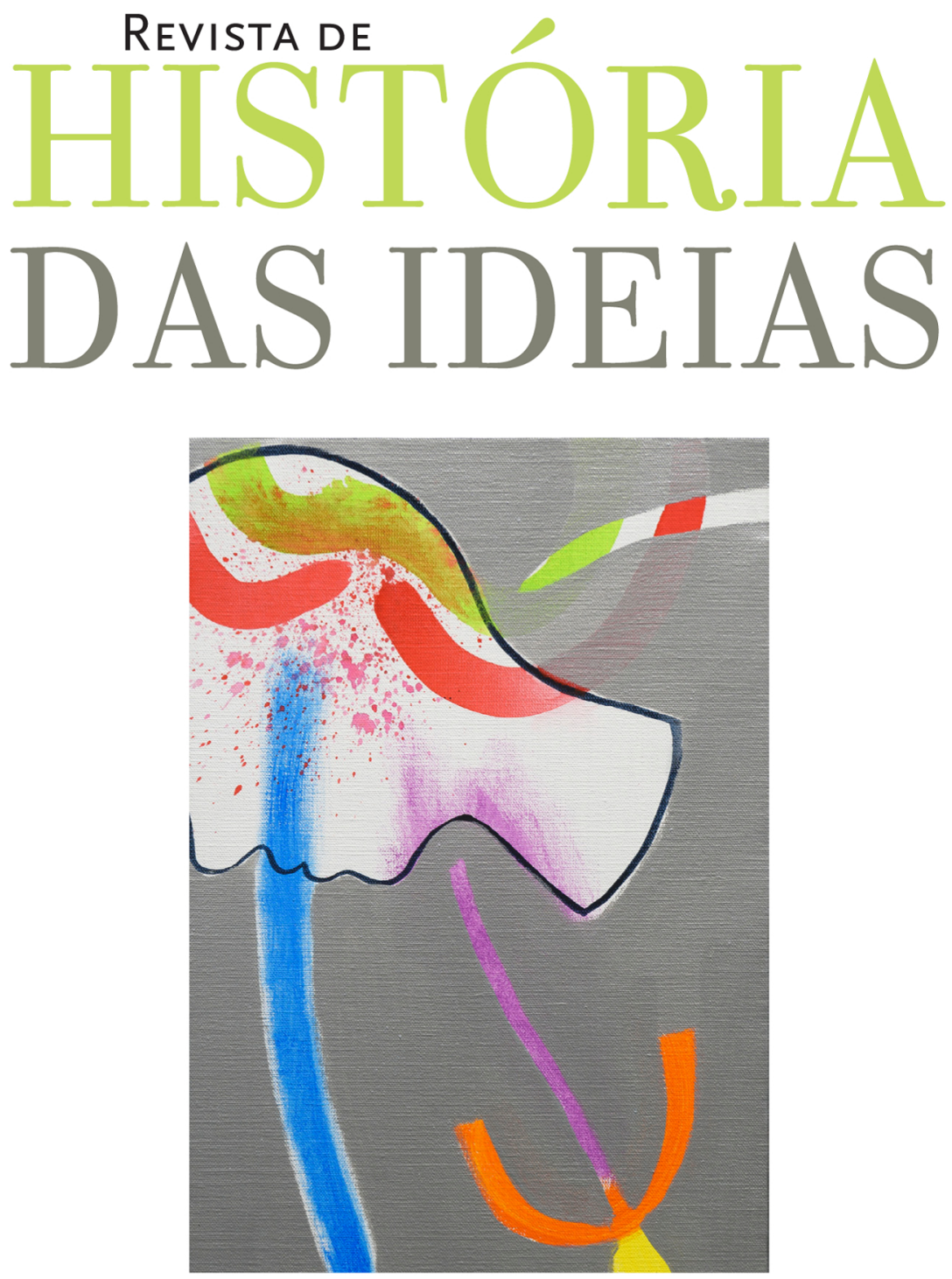

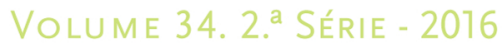




\section{RECENSÕES CRÍTICAS}

Francisco Régis Lopes Ramos, A poeira do passado. Tempo, saudade e cultura material, Fortaleza, Imprensa Universitária, 2014, 299 pp. ISBN: 978-85-7485-193-8

Este livro não é uma obra de História, nem mesmo, por certo, de Teoria da História. Mas é, sem dúvida, um interessante livro sobre História ou, talvez melhor, sobre o «Museu», que a História supõe e nos leva a ela. Daí a sua fixação, que percorre todo o livro, em Gustavo Barroso, cearense, museólogo e diretor durante décadas do Museu Histórico Nacional, sublinhando o autor mais esta sua posição e de importante intelectual - assim como o fizeram historiadores como Sérgio Buarque de Holanda - do que a sua militância ideológica de membro da Acção Integralista Brasileira e de antissemita confesso. De resto, Francisco Régis foi diretor do Museu Histórico do Ceará e não podia, pois, deixar de falar constantemente no seu Museu e nos seus antecessores, como Dias Rocha e Eusébio de Sousa.

Obviamente o tema do livro sintetiza-se no seu título ou, melhor, no seu subtítulo - «Tempo, saudade e cultura material» - e nos seus grandes capítulos, subdivididos depois em outros: «A Matéria», «Tempo», «A Palavra», «O Trânsito» e «A Trama». Com estes nomes sugestivos mas que valem sobretudo pelo seu caráter simbólico, vai-nos falando do sentido e da transformação das fontes - numa atração pelo passado e até num sentimento de «saudade» - e da sua transformação num discurso histórico, normalmente identificado como o mais próximo possível do objeto que se escolheu e se quer fazer notar. E assim vai percorrendo os espaços da história e como ela sofre mutações e esquecimentos, em função dos autores que a vão relatando e sentindo: historiadores, filósofos ou ficcionistas. Por isso raramente - ou talvez nunca-em alguma página deste livro se deixe de citar autores, autores 
diversos, que se complementam ainda numa bibliografia significativa, onde, obviamente, faltam outros autores e outras obras.

Digamos que talvez seja esta a questão que levanta o livro. São tantos os autores, profissional e ideologicamente diferentes, que, se não se cai numa contradição, se desemboca necessariamente em alguma complexidade no que se refere aos seus objetivos. O que pensa o autor sobre a História? Mesmo o que pensa ele sobre o Museu? A interrogação é a constante deste livro, mas ela surge menos do questionamento do autor perante o objeto, mas de uma série de discursos, de respostas e perguntas que os muitos autores (dezenas se não centenas) vão dando.

Francisco Régis é um viajante, não só quando viaja no espaço e no tempo - como me tenho apercebido, como seu companheiro de viagem -, mas também quando lê. E lê interminavelmente, até porque, ao contrário do que sucede em Portugal - posso dizê-lo desde os anos 60 do século passado, quando era estudante de História -, no Brasil quase tudo e quase todos os autores são traduzidos.

Não se trata, nem se pretendeu que assim fosse, do início de uma História da História do Brasil (quem dera que fosse, já que se perdeu há alguns anos o projeto que se gizou para Portugal e para o Brasil), nem uma interrogação sobre a História e a sua possível objetividade e sentido científico, nem uma reflexão histórica sobre o «Museu» ou os «Museus» - na sua diversidade de objeto material e oral relativo ao passado, que o arquiteto que restaura (e outro tipo de especialistas) e o museólogo mostra e transforma, como o historiador vai transformando cientificamente (assim se espera) as diversas fontes, e como o escritor vai recriando na sua ficção - mas é uma escrita que nos leva a pensarmos em tudo isto.

Numa «lição de jubileu» (prefiro esta expressão à comum «última lição»), Fernando Rosas referia há dias, polemicamente, que só a História - o seu conhecimento profundo e complexo - pode salvar o futuro. Referia-se, pois, a uma História que não seria composta para um determinado objetivo (recordava mesmo que hoje a História podia, ao invés do que faziam integralistas e salazaristas, ficar numa situação de aparente «neutralidade», cinzenta, que induzia a recuperar um certo passado com outros objetivos ideológicos, propositadamente menos definidos) e sim uma História que explicasse o que na verdade se pode inferir do conhecimento das suas marcas. Por isso o historiador, munido de conhecimentos mais densos do que a maioria dos outros cientistas sociais, deveria e poderia intervir na vida cívica, refletindo - não tanto como historiador, mas sobretudo como cidadão - sobre a «História do presente» (afinal todo o Presente é passado), ao mesmo tempo que se interroga sobre o seu Futuro. 
Não é esta a posição de Régis, que limita a sua reflexão à junção de discursos e ideologias, num exercício de saudável lazer intelectual. Que não esquece, todavia, que o Museu é hoje feito não tanto para mostrar as suas obras, de forma a que se verifique uma interrogação permanente em quem as vê, sente, ouve e cheira, mas para evidenciar «algumas» no sentido de criar ou condicionar a criação de «uma Memória» e de «uma História». Mas necessariamente o seu percurso terá de chegar, e chegou noutros livros, a uma lógica de objetividade: o que foi e é a História do Brasil, como processo que se projeta ao longo do tempo, como historiografia e como memória? O perigo que hoje encontramos é o que agora se chama de "Ciência Aberta», em que se perdeu a especificidade da História e ela se mistura com todo o tipo de conhecimento (a Internet tem favorecido esse percurso), numa conceção pouco clara de algo que se classifica-até nas livrarias - de «Ciências Sociais e Humanas», o que redunda normalmente num exercício de reflexão sem rumo certo, de mistura de conceitos pouco definidos, de saberes pouco especializados... O Mundo - este «Mundo plano»-é cada vez mais uma Grande Interrogação, mas a Resposta não vem de um saber amalgamado e, por vezes, fácil de seguir, que se propõe fazer Grandes Diagnósticos e dá, por vezes, Grandes Soluções, que se vem a perceber não o serem.

O livro de Francisco Régis Lopes Ramos sobre «A Poeira do Passado» leva-nos, pois, aos mundos diversos do Passado e será certamente completado - como já foi antecedido em outra obras mais académicas - por outros livros do autor, que virão a refletir de forma mais pessoal sobre a História e sobre as suas interrogações e possibilidades científicas e interventivas. É - repito - um belo livro que reflete sobre o que chama a «poeira do passado» («restolho do tempo» lhe chamou Fernando Catroga), e terá de ser completado por outras obras, quiçá diferentes mas que darão a este nova substância.

\section{LUÍS REIS TORGAL \\ Faculdade de Letras da UC lreistorgal@gmail.com https: / / doi.org/10.14195/2183-8925_34_13}

Sobre o conteúdo da forma

(Resposta à resenha do prof. Dr. Luís Reis Torgal)

Na recente arguição da tese de doutorado de Joelma Tito, que tive o prazer e o privilégio de orientar na UFC, o prof. Durval Muniz advertiu que as suas indagações não cobrariam, em princípio, cientificidade, e sim certas adequações ao estilo literário de uma tese de história. Entendido ficou que se estava diante de uma escrita com características próprias, ou melhor, articulada por lógicas discursivas particulares e composta por procedimentos 